\title{
Relativism, Particularism and Reflective Equilibrium
}

Abstract: In previous work, I have sought to show that the basic argument for epistemic relativism derives from the problem of the criterion that stems from ancient Pyrrhonian scepticism. Because epistemic relativism depends upon a sceptical strategy, it is possible to respond to relativism on the basis of an anti-sceptical strategy. I argue that the particularist response to scepticism proposed by Roderick Chisholm may be combined with a naturalistic and reliabilist conception of epistemic warrant as the basis for a satisfactory response to epistemic relativism. In this paper, I outline this particularist response to relativism, and provide further commentary on the relationship between naturalism and particularism. In addition, I set the approach in contrast with reflective equilibrium approaches in epistemology. I also briefly explore the connection between the particularist response to relativism and G.E. Moore's defense of an external world.

Keywords: epistemic relativism; Pyrrhonian scepticism; particularism; naturalism; reflective equilibrium 


\section{Relativism, particularism and reflective equilibrium}

\section{Introduction}

Epistemic relativism and scepticism reflect opposing philosophical stances. For the relativist, knowledge and justified belief depend upon epistemic norms that vary with context (e.g., culture, historical time-period or Kuhnian paradigm). The sceptic either rejects knowledge and justified belief outright or suspends judgment with respect to the existence or possibility of knowledge and justified belief.

But while relativism and scepticism stand opposed, they stem from a common source. As I have sought to show in previous work, the principal basis for epistemic relativism is the problem of the criterion, which may be traced back to Pyrrhonian scepticism. ${ }^{1}$ The problem of the criterion arises due to the impossibility of providing a justification for an epistemic norm which does not lead to infinite regress, circularity or dogmatic adoption of the norm without justification. $^{2}$ Where the Pyrrhonian suspends judgment, however, the epistemic relativist draws an alternative moral from the problem of the criterion. Since it is impossible to provide justification for any epistemic norm, no epistemic norm has greater justification than any other

\footnotetext{
${ }^{1}$ My claim that relativism and scepticism stem from a common source relates specifically to the Pyrrhonian problem of the criterion. The connection with other forms of scepticism, such as Cartesian scepticism, is indirect. But, as we will see in the final section, a connection may be made via G. E. Moore's commonsense particularist response to scepticism about the external world.

${ }^{2}$ I employ the term 'norm' as a general term for epistemic standards or rules to which appeal is made to justify a belief or to warrant acceptance of a theory. Hence, I regard the paradigmspecific rules of Kuhnian normal science as well as Kuhn's non-algorithmic values of theorychoice as examples of epistemic norms. Equally, I take the poison-oracle which Azande tribesmen employ as a basis for beliefs about witchcraft and everyday misfortunes as an epistemic norm as well. In the present context, I also take criteria in the sense relevant to Pyrrhonian scepticism to constitute epistemic norms.
} 
norm. All epistemic norms have equal status. So, the relativist concludes, epistemic justification is relative to the norms which are employed in specific local contexts.

The dependence of epistemic relativism on a sceptical argument has significant implications for the treatment of relativism. For if relativism depends on a sceptical argument it is possible to respond to it on the basis of an anti-sceptical strategy. In previous work, I have argued that a particularist response to the sceptic of the kind proposed by Roderick Chisholm may be combined with a naturalist and reliabilist view of epistemic warrant to provide a response to the relativist. The purpose of the present paper is to further develop the anti-sceptical response to relativism that I have presented in previous work. In this paper, I turn my attention to previously unexplored foundational aspects of my approach by further articulating the relationship between particularism and naturalism, contrasting particularist with reflective equilibrium approaches to epistemic justification, and indicating connections between the present approach to epistemic relativism and an overall philosophical outlook that is broadly realist with respect to both common sense and science.

The paper is divided into six sections. In section 2, I explain how epistemic relativism will be understood here, and show how it derives from the problem of the criterion. In section 3 , I characterize Chisholm's particularist response to the problem of the criterion before, in section 4, presenting my anti-sceptical approach to relativism. The particularist elements of this approach set it in opposition to reflective equilibrium approaches in epistemology. In section 5, I consider the relationship between particularism and the method of reflective equilibrium. Chisholm himself regarded G. E. Moore's response to scepticism about the external world as a prime example of particularism. This has interesting implications for the response to relativism which I will briefly mention by way of conclusion in section 6 . 


\section{Epistemic Relativism and the Problem of the Criterion}

In 'Scepticism, relativism and the argument from the criterion' (Sankey 2012), I have attempted to show that the principal argument for epistemic relativism derives from the Pyrrhonian problem of the criterion. ${ }^{3}$ In this section, I will present the argument for epistemic relativism that is based on the problem of the criterion. But before I turn to that I will first explain what is here meant by 'epistemic relativism'.

By epistemic relativism, I understand the view that there is no objectively correct system of epistemic justification. Instead, justification depends upon the epistemic norms which are employed within a particular local setting, such as a culture, a historical time-period or Kuhnian paradigm. $^{4}$ Because epistemic norms may vary from one context to another, epistemic justification likewise varies with context. Epistemic justification is relative to the epistemic norms that operate in particular cultural settings.

There are, of course, different forms of relativism. So it is important to be clear about the form of relativism presently at issue. According to epistemic relativism, knowledge and justified belief are relative to variable epistemic norms. However, knowledge requires true belief. I wish to focus specifically on epistemic relativism rather than on issues relating to relativism about

\footnotetext{
${ }^{3}$ Though I have independently developed this line of thought, the idea is not without precedent. For example, Williams $(2007,94)$ takes it to be the "fundamental argument for epistemic relativism".

${ }^{4}$ I find it natural to describe such local settings as contexts, and in general I will do so. However, it is important to note that contexts in the sense at issue here are different from the kinds of contexts at issue in contextualist epistemology. We are not here speaking of alternative contexts of discourse in which variable conversational presuppositions affecting knowledge attribution are in place. Rather, we are speaking of different cultures or intellectual contexts in which different epistemic norms may be employed. I devote a section to further exploration of the relationship between relativism and contextualism in 'Scepticism, Relativism and a Naturalistic Particularism' (forthcoming).
} 
truth. So I will focus here on relativism about justification rather than knowledge. The question of relativism about truth is distinct from the issue of relativism about epistemic justification, and is to be dealt with separately. So, too, are forms of relativism which involve alternative conceptual schemes and the dependence of reality on conceptual scheme. Such conceptual and ontological forms of relativism are not at issue here. ${ }^{5}$

What is at issue is the standing of the epistemic norms to which appeal is made to justify belief. There are, of course, a number of different arguments for relativism with respect to epistemic justification. ${ }^{6}$ However, I regard the most fundamental argument for epistemic relativism to be an argument that derives from the problem of the criterion. I call it the argument from the criterion. It may be presented in the following terms.

Consider any norm that may be proposed to justify belief. ${ }^{7}$ In order for such an epistemic norm to fulfil its justificatory role, it must itself be justified. But how is such a norm to be justified? Perhaps the norm may be justified by appeal to some further norm. But this just raises the question of how the further norm is to be justified, which leads to an infinite regress. To bring the regress to a halt, appeal may be made to the original norm, in which case the justification proceeds in a circle. The alternative is to adopt the norm without justification. But

\footnotetext{
${ }^{5}$ For further details concerning varieties of relativism, see my (2012, section 3.1), as well as my (1997, chapter 1).

${ }^{6}$ For example, in my (2012) I consider an argument from the diversity of values which may be employed due to the underdetermination of theories by data. I also consider two arguments described by Harvey Siegel, the argument from non-neutrality and the argument from perspective (Siegel 2011). However, I argue that these arguments are all less fundamental than the argument based on the problem of the criterion. I have developed my approach in detail in the context of a form of epistemic relativism which depends upon methodological incommensurability in my (2013b).

${ }^{7}$ I frame the argument in terms of norms rather than criteria because this is my preferred terminology. The argument may of course be framed in terms of criteria.
} 
in this case the norm is unjustified. So, in general, it is not possible to provide any proposed epistemic norm with a justification.

This line of reasoning leads the Pyrrhonian sceptic to the suspension of belief. ${ }^{8}$ However, the relativist draws another moral. The problem of the criterion reveals that it is impossible to provide any epistemic norm with a justification. The decision to adopt an epistemic norm may not, therefore, be made on a rational basis. Nor may any epistemic norm be better justified than any other norm. All epistemic norms have the same standing. Since it is not possible to provide a justification for any norm or set of norms, the only possible form of justification that remains is justification on the basis of the norms that are employed in specific local contexts. But in this case the beliefs justified on the basis of one norm (or set of norms) are as well justified as beliefs justified on the basis of any other norm (or set of norms). Thus, the justification of belief depends upon, and varies with, the norms that operate within local contexts. There is no justification over and above appeal to locally operative norms. Epistemic justification is relative to the epistemic norms that operate in specific local contexts. ${ }^{9}$

As may be seen, this argument on behalf of epistemic relativism is based on the Pyrrhonian problem of the criterion. Moreover, as I have shown in 'Epistemic relativism and the problem of the criterion' (Sankey 2011), it is an argument which has played an important role in the treatment of relativism by central figures in the history and philosophy of science. ${ }^{10}$ But I

\footnotetext{
${ }^{8}$ Note that I have formulated the problem of the criterion in the form of a trilemma. As I will mention later, Chisholm formulates the problem in a form that is known as the diallelus or wheel.

${ }^{9}$ In his comment on my approach to relativism, Markus Seidel objects that the sceptical basis for relativism prevents justification by operative norms from being genuine justification (Seidel, 2013, 136-7). In response, I distinguish between weak justification where a belief is justified by appeal to some norm and strong justification where the norm itself is also justified. The relativist allows weak justification, but denies that there may be strong justification. See my (2013a, 142).

${ }^{10}$ More specifically, in my (2011) I show that an argumentative strategy that draws significantly on the problem of the criterion features in the treatment of relativism by such figures as Barnes
} 
think that the fundamental flaw in the epistemic relativist position stems precisely from the appropriation of this sceptical line of argument, as I will explain in the section 4.

\section{Chisholm's Particularist Response to the Problem of the Criterion}

In the previous section, I have shown how epistemic relativism may be seen to rest on the sceptical problem of the criterion. This relationship between relativism and scepticism has important implications for the treatment of relativism. It affords the possibility of a response to relativism on the basis of a response to scepticism. However, before presenting my naturalistic response to the relativist, in this section I will present Chisholm's particularist response to the sceptic, which serves as the point of departure for my approach.

In The Problem of the Criterion, Chisholm frames the problem raised by Pyrrhonian scepticism in terms of two pairs of questions about knowledge:

(A) "What do we know? What is the extent of our knowledge?"

(B) "How are we to decide whether we know? What are the criteria of knowledge?"

(Chisholm, 1973, 12)

The first pair of questions relates to the substantive issue of what in fact we know. By contrast, the second pair of questions relates to the issue of how we determine that we know something.

There is, as Chisholm shows, an intimate relationship between the issues. On the basis of a response to the question of what we know, it would be possible to arrive at an answer to the question about the criteria of knowledge. Conversely, if we were in possession of criteria for knowledge, it would be possible to use the criteria to determine what in fact we know. But it is difficult to see how to answer one question without a prior response to the other. The reciprocal

and Bloor, Feyerabend, Kuhn, Laudan, Popper and Worrall, among others. I do not, of course, claim that all of these writers are relativists. My point is simply that the problem of the criterion plays an important role in thinking about relativism amongst key figures in the history and philosophy of science. 
relationship between the questions is the source of the problem of the criterion in the form in which Chisholm considers it. ${ }^{11}$

Chisholm distinguishes between three approaches that may be taken to the problem of the criterion. The first approach is to say that it is impossible to answer one question without first answering the other. Since it is impossible to answer one without first answering the other, it is impossible to answer either. Chisholm takes this approach to be that of the sceptic.

But the sceptical approach is not the only approach available. Apart from the sceptical response, there are two remaining approaches. Each is characterized by taking one question as prior to the other. One approach is to start with an answer to the question of the criteria of knowledge. Chisholm calls this approach methodism. The methodist adopts a view about the criteria of knowledge. On the basis of this view, the methodist undertakes to answer the question about what is in fact known. Thus, for the methodist, the question of the criteria of knowledge precedes the question of the extent of knowledge.

By contrast, it is possible to take the question of what is known as the prior question. We may start with uncontentious cases of knowledge. Chisholm takes G. E. Moore's commonsense assertion that he knows that he has hands as a prime example of such knowledge. We then proceed on the basis of such particular items of knowledge to the question of the criteria of knowledge. Based on examination of particular items of knowledge, we may develop criteria of "what it is for a belief to be epistemologically respectable" $(1973,24)$. In this way, particular instances of knowledge are prior to criteria of knowledge. Accordingly, Chisholm refers to the approach that starts with particular items of knowledge as particularism.

${ }^{11}$ The question of how it is possible to answer one of the questions without answering the other constitutes the form of the problem of the criterion that is known as the diallelus or the wheel. See my (2011, section 2.1) for different formulations of the problem by Sextus Empiricus. 
Of the three approaches, Chisholm himself favours the particularist approach. He objects to the methodist that to start with a criterion prior to identification of items of knowledge is to proceed in an arbitrary manner. But whereas Chisholm objects to the methodist, his response to the sceptic is simply to assume that we are in possession of knowledge. In other words, to deal with the problem of the criterion, he begs the question against the sceptic:

What few philosophers have had the courage to recognize is this: we can deal with the problem only by begging the question. It seems to me that, if we do recognize this fact, as we should, then it is unseemly for us to try to pretend that it isn't so.

One may object: "Doesn't this mean, then, that the sceptic is right after all?" I would answer: "Not at all. His view is only one of the three possibilities and in itself has no more to recommend it than the others do. And in favor of our approach there is the fact that we do know many things after all." (Chisholm, 1973, 37-8)

Chisholm's response to the problem of the criterion is, therefore, simply to insist that we are in possession of knowledge on the basis of which we may develop criteria of knowledge. There may be some who expect a response to the sceptic to provide a non-question-begging refutation of the sceptic. No doubt, they will be disappointed by Chisholm's apparent willingness to blatantly beg the question in the context of a response to the sceptic.

But for the naturalist the question-begging nature of Chisholm's response to scepticism is not particularly troubling. Naturalists have long held that sceptics and proponents of traditional Cartesian epistemology set the epistemic bar inappropriately high by taking certainty to be required to refute scepticism. For the naturalist, it is an error to uphold epistemic standards that are more rigorous than those to be found in ordinary common sense and scientific inquiry. Confronted with a sceptical challenge to the standards of common sense and science, the naturalist rejects the sceptical challenge as reflecting a mistaken epistemology. This may well 
amount to begging the question against the sceptic, as Chisholm admits in the case of his own response. But from a naturalistic perspective, such question-begging is not a cause for alarm. ${ }^{12}$

\section{Particularism and a Naturalist Response to Relativism}

Though Chisholm was no naturalist, there is a substantial point of overlap between his particularism and a naturalistic conception of knowledge. As just indicated, the epistemic naturalist rejects scepticism as resting on a mistaken view of knowledge. By contrast with the sceptic, the naturalist takes humans not only to be capable of knowledge but to be in possession of a considerable store of knowledge. Given the rejection of scepticism, the naturalist completely endorses the particularist view that a broad range of uncontentious cases of knowledge are to be accepted precisely as such. ${ }^{13}$

But while the naturalist and the particularist may agree that particular items of knowledge are genuine items of knowledge, there is a further convergence between the two views that is of greater relevance for our purposes. This relates to the appraisal of epistemic norms. For the particularist, it is possible to arrive at criteria of knowledge by inspecting particular items of

\footnotetext{
${ }^{12}$ Though the classic reference for naturalized epistemology is Quine (1969), formulations of a naturalistic approach which more explicitly articulate the opposition between naturalism and the sceptical concerns of Cartesian epistemology may be found in Devitt (1991, section 5.8) and Papineau (1992).

${ }^{13}$ Of course, while the naturalist may allow that particular items of knowledge are indeed items of knowledge, this does not entail that the naturalist is necessarily a particularist. I take there to be a close affinity between naturalism and particularism. However, a naturalist might be tempted to adopt a methodist stance. Such a methodist naturalist might take particular items of knowledge to constitute knowledge in virtue of their satisfaction of the criteria. But, while this may be a possible position, such a methodist naturalist must confront Chisholm's point that the choice of epistemic criteria prior to identification of particular instances of knowledge must surely be arbitrary. Suffice to say that I regard particularism and naturalism to be a more natural fit than methodism and naturalism.
} 
knowledge. This particularist approach to the development of criteria of knowledge is similar in spirit to the naturalistic conception of the appraisal of epistemic norms.

For the epistemic naturalist, epistemology is a broadly empirical discipline. ${ }^{14}$ We learn how to conduct inquiry as a result of inquiry itself. The epistemic norms that are developed in the course of inquiry are evaluated on the basis of inquiry. As Larry Laudan has argued, epistemic norms are themselves based on hypotheses about how to conduct inquiry into the world in which we find ourselves (e.g., Laudan, 1996, 133, 156-7). Hypotheses about the proper conduct of inquiry are subject to empirical evaluation on the basis of the outcome of inquiry itself. It is an empirical matter whether a proposed norm of inquiry constitutes a satisfactory means of inquiry into the world we inhabit.

From this naturalistic perspective, it is possible to approach the question of epistemic normativity on an empirical basis. It is a matter of satisfactory performance in the pursuit of epistemic goals. An epistemic norm is to be evaluated by determining whether its use leads to the realization of epistemic goals such as truth or empirical confirmation. ${ }^{15}$ A norm whose use leads on a regular basis to an epistemic goal such as truth is a reliable norm able to convey

\footnotetext{
${ }^{14}$ It may be objected that mathematics and logic are not empirical, so that the epistemology of such areas must be a priori. I do not wish to enter this dispute here. Suffice to say that the naturalist may respond in various ways, for example by insisting that even such seemingly $a$ priori disciplines are in fact empirical or perhaps by allowing that even an empirical discipline must involve non-empirical elements.

${ }^{15}$ Here a comment is in order in relation to the possibility of epistemic goals other than truth and empirical confirmation. Epistemologists may tend to assume that truth is the only epistemic goal. But in the philosophy of science, there has been significant dispute about the aims of science. While scientific realists hold that the aim of science is truth, aims such as empirical adequacy, predictive accuracy, overall simplicity and practical control over the environment have been advocated by anti-realist philosophers of science. Laudan's account of the appraisal of epistemic norms is not committed to any particular aim of science.
} 
epistemic warrant to beliefs formed on the basis of the norm. A norm whose use does not reliably give rise to relevant epistemic goals fails to provide justification for beliefs. ${ }^{16}$

The simple point that not all norms may perform their task equally well is all that is needed to defeat the relativist. Before developing this point in further detail, it is important to note the particularist elements of the naturalistic account of epistemic normativity that I have just outlined. For Chisholm, it is possible to arrive at epistemic criteria by inspection of particular cases of knowledge. This particularist approach may be combined with the naturalistic view that epistemic norms are subject to empirical appraisal. For, if the reliability of an epistemic norm is to be evaluated on an empirical basis, the evaluation of the norm is undertaken on the basis of empirical knowledge. Such evaluation proceeds in the manner suggested by Chisholm, since particular instances of empirical knowledge are employed as the basis for the evaluation of the norms. The naturalistic approach to epistemic normativity is therefore particularist in the sense that it makes the evaluation of epistemic norms depend upon particular instances of knowledge which serve as evidence for the reliability of the norms.

To return to the point about relativism, the crucial point is that there is no need to allow that all norms have equal epistemic standing. Not all norms perform equally well. Some norms conduce to epistemic goals such as truth, and are able to convey epistemic warrant. Other norms fail to lead reliably to such goals, so are unable to provide warrant. Thus, there is no need to concede to the relativist that justification is relative to locally operative norms. If operative norms are unreliable, the beliefs produced under their auspices are unjustified. Justification is

\footnotetext{
${ }^{16}$ My principal source for the idea that epistemic norms may be subject to empirical appraisal as reliable means to epistemic goals is the normative naturalism of Larry Laudan (1996, chapters 7 and 9), as well as the methodological pragmatism of Nicholas Rescher (1977). Where my version of this approach differs particularly from Laudan's normative naturalism is that I place the approach within a realist framework which takes truth to be an attainable cognitive aim (see Sankey, 2000).
} 
not relative to locally operative norms because not all norms are capable of justifying belief. Some norms are objectively better than others.

In sum, the combination of naturalism with particularism enables us to pinpoint the fundamental flaw in the epistemic relativist position. The relativist mistakenly concludes from the problem of the criterion that all norms have equal standing. The mistake is to assume that we may not have knowledge without prior identification of criteria. But we do have knowledge. Moreover, particular instances of knowledge may be utilized in the evaluation of competing epistemic norms. Given our possession of knowledge, there is no need to concede the equivalence of all such norms. ${ }^{17}$

\section{Particularism vs. Reflective Equilibrium}

In the previous two sections, I have presented Chisholm's particularist response to the problem of the criterion, as well as my own proposal to combine particularism with a naturalist account of warrant. This combination provides the basis for the approach to epistemic relativism which I first proposed in 'Witchcraft, relativism and the problem of the criterion' (Sankey, 2010). To further develop this approach, I now undertake two tasks. In this section, I explore the relationship between particularism and the method of reflective equilibrium. In the final section, I briefly sketch implications for relativism which arise due to the particularism of Moore's commonsense realism.

${ }^{17}$ This response to the relativist takes relativism to be mistaken because some norms are objectively better than others. Of course, one might seek a stronger response to the effect that there is one uniquely correct set of epistemic norms. As opposed to such a "monistic" or "absolutist" approach, I favour a pluralist view which allows that there may be multiple norms (or sets of norms) capable of providing genuine epistemic warrant. (See my (2000) for a development of this view with respect to the methodology of science.) 
The method of reflective equilibrium is a method of justification whereby judgments about particular cases are brought into conformity with general principles. The method was introduced by Nelson Goodman in the context of the problem of induction. Goodman claimed that inductive inferences are justified in the same way that deductive inferences are justified. Particular inferences are justified on the basis of general rules. For their part, rules are themselves justified by means of a balance that is struck between rules and actual inferential practice. As Goodman famously put it, "A rule is amended if it yields an inference we are unwilling to accept; an inference is rejected if it violates a rule we are unwilling to amend" (Goodman, 1979, 64; italics in original). Justification emerges as the result of a process of mutual adjustment between our actual practice of inference and proposed general rules or principles. The mutual adjustment produces agreement "between rules and accepted inferences" which provides "the only justification needed for either" $(1979,64)$.

Goodman originally applied the method of reflective equilibrium to inference. However, it has since been more generally employed in a range of areas concerned with matters of normativity. The method is frequently employed in moral philosophy in the justification of moral judgments and principles. Indeed, the expression 'reflective equilibrium' was not itself due to Goodman, but was introduced by John Rawls in The Theory of Justice. The method is also employed by epistemologists. For example, Alvin Goldman explicitly appeals to the "Goodman-Rawls conception" of reflective equilibrium in his attempt to identify a suitable criterion for the evaluation of rules of justification (Goldman,

1986, 66). In all of these areas a distinction may be made between "narrow reflective equilibrium" in which judgments and principles relate to a restricted domain, and "wide reflective equilibrium" in which a broader range of considerations is taken to be relevant. 
Chisholm's particularism is sometimes compared to the method of reflective equilibrium. For example, in Common Sense: A Contemporary Defense, Noah Lemos places particularism squarely in the common sense tradition (Lemos, 2004, 6). Lemos sees a parallel between the common sense tradition, which he takes to be particularist, and the method of reflective equilibrium:

I suggest that the common sense tradition is compatible with the method of wide reflective equilibrium. The common sense philosopher begins with various considered judgments, general principles, and background theories and attempts, insofar as he can, to bring them into reflective equilibrium. He wants his philosophical theories and his criteria of knowledge and evidence to fit and cohere with his considered particular judgments, including his considered particular judgments about common sense propositions. (Lemos, 2004, 9)

Thus, for Lemos, particularist philosophers in the common sense tradition may make use of the method of reflective equilibrium. The particular instances of knowledge to which such philosophers draw attention are to be brought into a relation of equilibrium with our general principles and background theories.

In a review of Lemos (2004), John Greco has criticized Lemos' treatment of the relation between particularism and reflective equilibrium. Greco objects to the claim that particularism is compatible with the method of wide reflective equilibrium:

... Lemos has characterized the common sense tradition as endorsing particularism, and it is not clear that the method of reflective equilibrium is consistent with particularism. Indeed, the method would seem to be a third methodology in epistemology. It recommends that we begin with both our intuitions about particular cases and our beliefs about general principles, and that we bring these into a coherent equilibrium. On this view, neither our intuitions about particular cases nor our beliefs about general principles should be privileged methodologically. (Greco 2005)

In saying that reflective equilibrium may be a third methodology, Greco is contrasting it with particularism and methodism. The method of reflective equilibrium differs from both methodism and particularism by granting equal weight to particular cases and general principles. But, Greco 
notes, this conflicts with common sense particularism, for which "common sense beliefs (including beliefs about what is known in particular cases) ought to be privileged over philosophical theories" (Greco 2005). If Greco is right, there is a conflict between the role granted by the particularist to particular instances of knowledge and the equal weight granted by the method of reflective equilibrium to particular cases and general principles.

At first blush, it may seem possible to reconcile particularism with reflective equilibrium in a way that meets Greco's objection. For there is a sense in which the uncontentious items of knowledge highlighted by the particularist may cohere with background beliefs and principles. To see this, let us consider as example the belief expressed by Moore's assertion, "Here is one hand and here is another", namely the belief that he has two hands which he is holding up. The belief is a perceptual belief, so does not depend on a rule for justification. But it would not be held if it failed to cohere with background beliefs such as the belief that one's hands are intact or that one's eyesight is reliable. Moore's belief that he has two hands is not an unreflective belief, but something that he knows to be true. It is a considered judgment that coheres with other beliefs. There is a sense in which it must cohere with background beliefs and general principles. Given this, there is a sense in which an item of knowledge of the kind highlighted by the particularist may enter into reflective equilibrium with other beliefs and principles.

This line of thought may suggest that particularism can be reconciled with the method of reflective equilibrium. But even if particular items of knowledge reflect considered judgment, this would not suffice to reconcile particularism with reflective equilibrium. The reason is that it is not entirely clear how particularism is to be understood. Greco treats particularism as a methodology that is to be employed in the construction of an epistemological theory rather than 
as itself an epistemological theory. ${ }^{18}$ By contrast, Lemos interprets particularism as a metaepistemological theory about the nature of epistemic knowledge, according to which "our knowing general epistemic principles depends on our knowing particular epistemic propositions" $(2004,108)$. Considered as a methodology for theory construction, particularism tells us to take particular instances of knowledge as a starting-point on the basis of which to build an epistemological theory. But, if particularism is instead construed as a meta-epistemology, then it tells us that knowledge of an epistemic norm depends upon particular items of knowledge. On such a construal, it is not a matter of how to build an epistemological theory, but a question of how knowledge that is epistemic in nature is justified on the basis of particular items of knowledge. ${ }^{19}$

In order to reconcile particularism with reflective equilibrium, it would need to be determined precisely how to understand both doctrines. The matter is further complicated by the fact that Chisholm does not himself state precisely how he understands particularism. Indeed, some of Chisholm's remarks seem to fit both interpretations. But it is possible to sidestep the issue of whether particularism is methodology or meta-epistemology. However it is construed, a clear difference remains between particularism and the method of reflective equilibrium.

As against reflective equilibrium, the particularist does not place general principles on a par with particular instances of knowledge. Greco is right that judgments about particular cases are privileged. This may be seen from what Chisholm says in describing particularism in the following passage:

\footnotetext{
${ }^{18}$ In treating particularism as a methodology, Greco follows Michael DePaul. For the idea that particularism is a methodology see, for example, DePaul (1988).

${ }^{19}$ In taking particularism as a meta-epistemology, Lemos follows Ernest Sosa, who writes that "particularism and methodism are meta-epistemological positions, for they tell us which justifies which of two sorts of epistemic knowledge" (Sosa, 1980, 558).
} 
As "particularists" in our approach to the problem of the criterion, we will fit our rules to the cases .... Knowing what we do about ourselves and the world, we have at our disposal certain instances which our rules or principles should countenance, and certain other instances which our rules or principles should rule out or forbid. And, as rational beings, we assume that by investigating these instances we can formulate criteria that any instance must satisfy if it is to be countenanced and we can formulate other criteria that any instance must satisfy if it is to be ruled out or forbidden. $(1973,35-6)$

There is no suggestion here that judgments about particular cases are to be brought into balance with general principles. Instead, it is the rules or principles that are to be made to fit with the particular cases. As a particularist, Chisholm seems not to have held that particular cases and general principles are to be brought into reflective equilibrium by a process of mutual adjustment. Indeed, it is hard to see why the particularist should be prepared to give up particular items of knowledge due to conflict with principles. After all, particularism is the position that knowledge is prior to criteria of knowledge. If that is so, it is not for knowledge to bow to criteria, but for criteria to bow in the presence of knowledge.

\section{Conclusion: Moore as Antidote to Relativism?}

In this paper, I have further developed an approach to epistemic relativism for which I have argued in a series of previous papers. The approach draws significantly on Chisholm's particularist response to the sceptical problem of the criterion. The novelty of the approach consists in identifying the problem of the criterion as the source of epistemic relativism, and in combining the particularist response to the sceptic with a naturalistic and reliabilist conception of epistemic warrant. As we have seen in this paper, the particularist elements of this approach bring it into some tension with the method of reflective equilibrium. I wish finally to draw attention to a further implication of the particularist aspects of this position. In light of the 
particularism of G. E. Moore's appeal to common sense, the present approach to epistemic relativism may be seen to involve a commonsense realist outlook as a central feature.

As mentioned at the outset, the focus of the paper is epistemic relativism rather than forms of relativism which involve truth, reality or alternative conceptual schemes. The reason for this restriction of focus is that my approach is designed specifically as a response to the relativist claim that epistemic justification is relative to locally operative epistemic norms which vary from context to context. The combination of Chisholm's particularist response to the problem of the criterion with the naturalist conception of epistemic warrant is intended specifically as a response to epistemic relativism understood in that sense. The arguments that I have presented on behalf of this approach to epistemic relativism are not intended as arguments against such other forms of relativism as relativism about truth, reality or conceptual scheme.

This is not to deny, however, that the present approach to epistemic relativism is meant to fit into a larger anti-relativistic perspective that is generally realist in outlook. ${ }^{20}$ We may begin to discern how the approach fits into this larger perspective if we now attend to the commonsense realist aspects of Chisholm's particularism. In drawing upon Chisholm's response to the Pyrrhonian sceptic, I have been primarily concerned to employ the particularist approach as a response to sceptical problems which relate to the justification of epistemic norms. This is why the particularist response is so helpful in relation to epistemic relativism. But there is, of course, another form of scepticism to which such particularism is relevant, namely scepticism about the external world.

20 Though I here focus on the relationship between epistemological particularism and commonsense realism, I hold that scientific realism is an outgrowth of common sense. This ensures that the present approach to epistemic relativism may be integrated with scientific realism. Thus, the generally realist outlook to which I refer in the text is a position which regards commonsense realism and scientific realism as combining to form a single, unified stance. 
Chisholm takes Moore's claim that he knows that he has hands to be a particularly clear example of particularism. But Moore's point that he knows he has hands is part of his proof of an external world, which plays a role in the defense of commonsense realism. We may reject the sceptical view out of hand, as it were, because any denial of an external world is less plausible than the commonsense view that we inhabit an external world with which we engage in our mundane activities. As commonsense particularists, we should believe that the world that we inhabit is by and large the world as we perceive it, and as we believe it to be. To think otherwise is to enter into the implausible realm of the sceptic or the idealist.

But now we find that as particularists we not only avoid the problem of the criterion, but we may also reject scepticism about the ordinary world of common sense. If this is right, then not only is there no risk that all epistemic norms are equally justified, but we may appeal to our commonsense view of the world in responding to the challenge of relativism. That is no small gain from the turn to particularism.

\section{Acknowledgements}

I am grateful to anonymous referees for comments which have enabled me to introduce a number of improvements into this paper. 


\section{References}

Chisholm, R. (1973). The problem of the criterion: The Aquinas lecture 1973. Milwaukee: Marquette University Press.

DePaul, M. (1988). The problem of the criterion and coherence methods in ethics. Canadian journal of philosophy, 18, 67-86.

Devitt, M. (1991). Realism and truth, $2^{\text {nd }}$ ed.. Oxford: Blackwell.

Goldman, A. (1986). Epistemology and cognition. Cambridge, Mass.: Harvard University Press.

Goodman, N. (1979). Fact, fiction and forecast (3rd ed.). Sussex: Harvester Press.

Greco, J. (2005). Review of Noah Lemos, Common sense: A contemporary defense. Notre Dame Philosophical Reviews, 2005/07/05.

Laudan, L. (1996). Beyond positivism and relativism. Boulder, Co.: Westview Press.

Lemos, N. (2004). Common sense: A contemporary defense. Cambridge: Cambridge University Press.

Papineau, D. (1992). Reliabilism, induction and scepticism. The Philosophical Quarterly, 41, 120.

Quine, W.V.O. (1969). Epistemology naturalized. In Ontological relativity and other essays (pp. 69-90). New York: Columbia University Press.

Rawls, J. (1971). A theory of justice. Cambridge, Mass: Harvard University Press. 
Rescher, N. (1977). Methodological pragmatism. Oxford: Basil Blackwell.

Sankey, H. (1997). Rationality, relativism and incommensurability. Aldershot: Ashgate.

Sankey, H. (2000). Methodological pluralism, normative naturalism and the realist aim of science. In R. Nola and H. Sankey (Eds.), After Popper, Kuhn and Feyerabend: Recent issues in theories of scientific method (pp. 211-230). Dordrecht: Kluwer.

Sankey, H. (2010). Witchcraft, relativism and the problem of the criterion. Erkenntnis, 72, 1-16.

Sankey, H. (2011). Epistemic relativism and the problem of the criterion. Studies in history and philosophy of science A. 42, 562-570.

Sankey, H. (2012). Scepticism, relativism and the argument from the criterion. Studies in History and Philosophy of Science A, 43, 182-190.

Sankey, H. (2013a). How the epistemic relativist may use the sceptic's strategy: A reply to Markus Seidel. Studies in History and Philosophy of Science A 44, 140-144.

Sankey, H. (2013b). Methodological incommensurability and epistemic relativism. Topoi, 32, $33-41$.

Sankey, H. (forthcoming). Scepticism, relativism and a naturalistic particularism. Social Epistemology.

Seidel, M. (2013). Why the epistemic relativist cannot use the sceptic's strategy: A comment on Sankey. Studies in history and philosophy of science A, 44, 134-139. 
Siegel, H. (2011). Epistemological relativism: Arguments pro and con. In S.D. Hales (Ed.) A companion to relativism (pp. 201-218). West Sussex: Wiley-Blackwell.

Sosa, E. (1980). The foundations of foundationalism. Nous, 14, 547-564.

Williams, M. (2007). Why (Wittgensteinian) Contextualism is not Relativism. Episteme, 4, 93114. 


\section{University Library}

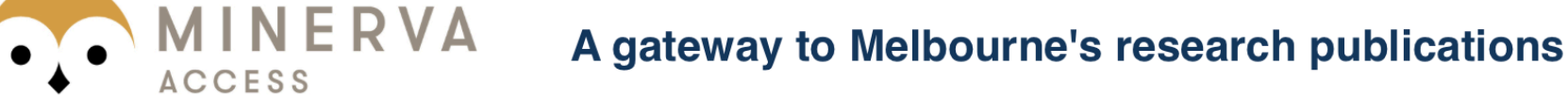

Minerva Access is the Institutional Repository of The University of Melbourne

Author/s:

Sankey, $\mathrm{H}$

Title:

Relativism, Particularism and Reflective Equilibrium

Date:

2014-11-29

Citation:

Sankey, H. (2014). Relativism, Particularism and Reflective Equilibrium. Journal for General Philosophy of Science, 45 (2), pp.281-292. https://doi.org/10.1007/s10838-014-9253-9.

Persistent Link:

http://hdl.handle.net/11343/282760 